\title{
Perceived Addictiveness of Smartphone Games: A Content Analysis of Game Reviews by Players
}

\author{
Janarthanan Balakrishnan $^{1} \cdot$ Mark D. Griffiths $^{2}$ (D)
}

Published online: 27 March 2018

(C) The Author(s) 2018

\begin{abstract}
The playing of videogames can be fun and entertaining, but research has consistently shown that a small minority of players experience problematic gaming. Most research to date has focused on online gaming via personal computers and laptops. However, gaming has evolved both in the games that are played and the platforms on which they can be played. One of the biggest growth areas has been in the area of smartphone gaming. The present study investigated the reasons for perceived smartphone game addiction by the users themselves, and how these perceptions compared across different smartphone game genres by analyzing reviews of smartphone games by the users themselves. The data comprised 25,200 game reviews of 140 smartphone games across 14 game genres to examine the most influential factors in addictive smartphone gaming by the individuals that play such games. Game reviews which were written under the heading of "addiction" or "addictive" were content analyzed to understand the most important variables associated with what makes a game "addictive" from a player perspective. Results indicated nine keywords (or their synonyms) to be strongly associated with smartphone games classed as "addictive" (i.e., "challenging," "entertainment," "friends and family," "gameplay," "creative," "graphics/animation," "fun," "free from advertisement," and "time killer"). The most common keyword associated with a smartphone game being "addictive" was "challenging" $(n=5636)$. The 14 genres clustered into five different categories based upon the identified nine keywords. Given the fact that there has been little published to date in the area of addictive smartphone gaming, the present paper is of existential value.
\end{abstract}

Keywords Gaming addiction · Smartphone gaming addiction $\cdot$ Challenging games $\cdot$ Mobile game addiction $\cdot$ Videogame genres

Janarthanan Balakrishnan reachjanarthanan@gmail.com; janarthanan@tsm.ac.in

Mark D. Griffiths

mark.griffiths@ntu.ac.uk

1 Thiagarajar School of Management, Madurai, India

2 International Gaming Research Unit, Psychology Department, Nottingham Trent University, Nottingham NG1 4BU, UK 
Videogame playing can be fun and entertaining, and there are many studies that highlight how highly engaged gaming can provide many social and psychological rewards (e.g., Charlton and Danforth 2007; Cole and Griffiths 2007; Griffiths et al. 2003; Yee 2006). There are also studies showing that some gamers immerse within the game that can result in problematic usage (e.g., Lemmens et al. 2011; Peters and Malesky 2008; Pontes et al. 2017; Rehbein et al. 2010; van Rooij et al. 2010). The deep immersion in playing videogame can be both a conscious and unconscious action, and for a minority of players, they can perceive themselves as being addicted to gaming (Kuss and Griffiths 2012).

Videogame addiction has become increasingly researched over the past two decades (e.g., Fisher 1994; Gentile 2009; Griffiths 2000; Mehroof and Griffiths 2010; Grüsser et al. 2007; Kuss and Griffiths 2012). However, researchers have noted that high engagement in games should not be mistaken with a gaming addiction (Charlton and Danforth 2007; Griffiths 2010). The context of gaming is also an important determinant as to whether the behavior is classed as engaging or addictive (Longman et al. 2009; Lim and Lee 2009; Wang and Wang 2008; Cole and Griffiths 2007). Griffiths (2010) argues that videogame addiction should be examined based on the context and consequences of the behavior. He demonstrated that excessive videogame use does not always lead to problematic gaming and that the number of hours spent playing videogames is not necessarily a core indicator of problematic gaming.

Alongside increased research, gaming has continued to evolve both in the games that are played and the platforms on which they can be played. One of the biggest growth areas has been in the area of smartphone gaming via Android and iOS (iPhone operating system) platforms (Billieux et al. 2015). Smartphones (and the games played upon them) have become pervasive as evidenced by their use almost anywhere (e.g., public transport, restaurants) as well as in situations where their use is illegal or frowned upon (e.g., while driving, in school classrooms) (Billieux et al. 2015). The revenue pattern of smartphone games is dependent upon downloads of the game, and many game developers make games available free of charge (at least initially-so-called freemium games; Griffiths 2013) with money being made by selling advertising space. Smartphone games have quickly become one of the "new faces" of the gaming industry. Furthermore, many smartphone games require repeated use to progress, and games are constantly updated to maintain player interest.

Most previous research examining problematic online gaming has been done by investigating the use of massively multiplayer games played via platforms such as laptops and personal computers (PCs). However, gaming needs to be revisited in the context of smartphone usage. Earlier studies examining other potentially addictive behaviors had shown that individuals do not perceive themselves as being addicted to activities such as smoking cigarettes (Eiser et al. 1985), pornography consumption (Grubbs et al. 2015), and drinking alcohol (Charuvastra et al. 2002). Anecdotally, this is not true in the case of smartphone gaming, particularly when looking at the reviews that players provide for smartphone games in gaming magazines. Consequently, the present study uses magazine gaming reviews as a data source to dissect and understand the contexts that contribute to perceived addiction as a novel addition to the gaming addiction literature.

Hundreds of smartphone games are now available in many different genres. The present study explored the reasons underlying perceived smartphone game addiction from the gamer's perspective across different smartphone gaming genres (e.g., action, adventure, arcade, board games, card games, casino, casual, educational, music, puzzle, racing, role-playing, simulation, sports, strategy, trivia, and word games). Although the gaming literature has provided numerous conceptual models in explaining online videogame addiction, there is little 
empirical literature concerning the reasons for addiction with smartphone games. Consequently, the present study investigated the reasons for perceived smartphone game addiction by the users themselves, and how these perceptions compared across different game smartphone game genres.

\section{Methods}

\section{Procedure}

The present research study utilized secondary data analysis of a large qualitative dataset comprising game reviews as a way of investigating perceptions surrounding what makes a smartphone game "addictive." Data collection for the main study followed a pilot study which was carried out to understand the role of the word "addiction" and "addictive" in smartphone game reviews. In the pilot study, 6000 reviews were analyzed across 17 categories of games available in the Google Play store (Android mobile operating system). Apart from games in the educational, music, and simulation game categories, the remaining 14 game categories (i.e., action, adventure, arcade, board games, card games, casino, casual, puzzle, racing, role-playing, sports, strategy, trivia, and word games) had significant presence of the word "addiction" in the reviews (see sample screenshots in Appendix 1). The pilot study also found that the words or phrases most commonly used in reviews that described the games as "addictive" were the following nine words: "challenging," "entertainment," "friends and family," "gameplay," "creative," "graphics/animation," "fun," "free from advertisement," and "time killer."

Based on the results of the pilot study, 14 game categories and nine variables were considered for the main study. Reviews were subsequently collected from 140 "top ten" games across 14 different categories in the Google Play store (see Appendix 2 for a list of the 140 games). A total of 25,200 reviews were collected containing reference to the game being addictive (1800 reviews in each of the 14 categories). The reviews mostly contained the nine keywords directly associated with addiction that were found in the pilot study. However, some reviews reported synonymous words representing the nine keywords. For example, the words "tough task," "hard objective," and "hard to play" are words or phrases meaning "challenging." Similar situations arose for the other eight keywords. Content analysis was used to analyze the data collected. The objective of the data analysis was twofold. The first was to tabulate the most cited of the nine keywords (or their equivalents) in gaming reviews that mentioned the smartphone game being addictive. The second was to understand the role of nine keywords (or their synonyms) across the 14 different game genre categories in gaming reviews that mentioned the smartphone game as being "addictive." Data analysis took one complete month with 15 research students involved in the data coding.

\section{Analysis}

Considering the exploratory nature of the research paper, first a nominal frequency table was constructed providing the most commonplace keyword (or their synonym) in smartphone game reviews that mentioned the videogame was "addictive." The distribution table provides overall results and findings by videogame genre category. Following which, and considering the data type, the frequency table was used to cluster the game categories (Table 1). Following this, a clustering methodology was performed using two main steps. First, the similarity matrix 
Table 1 Frequency distribution of keywords (or their synonyms) by game genres in reviews that mentioned the smartphone game as being "addictive"

\begin{tabular}{|c|c|c|c|c|c|c|c|c|c|c|}
\hline $\begin{array}{l}\text { Game } \\
\text { genre }\end{array}$ & 1 & 2 & 3 & 4 & 5 & 6 & 7 & 8 & 9 & Total \\
\hline Action & 456 & 342 & 256 & 220 & 165 & 152 & 110 & 61 & 38 & 1800 \\
\hline Adventure & 280 & 226 & 292 & 215 & 315 & 325 & 112 & 20 & 15 & 1800 \\
\hline Arcade & 112 & 256 & 156 & 382 & 267 & 215 & 195 & 20 & 197 & 1800 \\
\hline Board & 420 & 115 & 697 & 95 & 110 & 115 & 120 & 47 & 81 & 1800 \\
\hline Card & 417 & 220 & 512 & 115 & 28 & 115 & 190 & 71 & 132 & 1800 \\
\hline Casino & 313 & 471 & 342 & 143 & 86 & 78 & 221 & 23 & 123 & 1800 \\
\hline Casual & 312 & 476 & 132 & 214 & 176 & 183 & 168 & 22 & 117 & 1800 \\
\hline Puzzle & 585 & 255 & 136 & 112 & 182 & 176 & 135 & 107 & 112 & 1800 \\
\hline Racing & 286 & 174 & 122 & 202 & 216 & 412 & 192 & 23 & 173 & 1800 \\
\hline $\begin{array}{l}\text { Role } \\
\text { playing }\end{array}$ & 412 & 211 & 76 & 212 & 196 & 304 & 203 & 76 & 110 & 1800 \\
\hline Sports & 233 & 198 & 322 & 422 & 120 & 298 & 101 & 28 & 78 & 1800 \\
\hline Strategy & 112 & 102 & 802 & 156 & 156 & 212 & 135 & 83 & 42 & 1800 \\
\hline Trivia & 886 & 121 & 89 & 137 & 109 & 146 & 99 & 109 & 104 & 1800 \\
\hline Word & 812 & 133 & 23 & 89 & 98 & 109 & 123 & 112 & 301 & 1800 \\
\hline Numbers & 5636 & 3300 & 3957 & 2714 & 2224 & 2840 & 2104 & 802 & 1623 & 25,200 \\
\hline$\%$ & 22.36 & 13.09 & 15.70 & 10.77 & 8.83 & 11.27 & 8.34 & 3.19 & 6.45 & 100 \\
\hline
\end{tabular}

The numbers in italics represent the words that scored highest across each game genre

$1=$ Challenging; $2=$ Entertainment; $3=$ Friends and Family; $4=$ Gameplay; $5=$ Creative; $6=$ Graphics and Animation; 7 = Fun; 8 = Free From Advertisements; $9=$ Time Killer

between the 14 game categories controlled by nine addiction keywords was created using Euclidean distance mapping. Second, the game categories were clustered using hierarchical model with an agglomeration schedule (Table 2).

\section{Results}

Among all the keywords (and their synonyms), the keyword "challenging" ( $n=5636$; $22.37 \%$ ) was found to have the strongest association with a smartphone game being addictive, followed by "friends and family" ( $n=3957 ; 15.7 \%)$ and "entertainment" $(n=3300 ; 13.1 \%)$. The distribution of keywords by game genre is shown in Table 1 . The results also showed that the keywords influencing "addictive" games varied across the game genres. Analysis showed that the most important keyword for "addictive" smartphone games described as being "challenging" were action $(n=456)$, puzzle $(n=585)$, role-playing $(n=412)$, trivia $(n=$ $866)$, and word games $(n=812)$. For casino and casual games, the "addictive" keyword most reported was "entertainment" ( $n=471$ and $n=476$ respectively). For board games, card games, and strategy games, the most reported keyword was "friends and family" $(n=697$, $n=512$, and $n=802$ respectively). For arcade and sports games, the most reported keyword was "gameplay" ( $n=382$ and $n=422$ respectively). Finally, the most reported keyword associated with adventure and racing games being "addictive" was "graphics and animation" ( $n=325$ and $n=412$ respectively). Figure 1 shows the distribution of the nine keywords associated with "addictive" games across the 14 game genres.

Table 2 provides the values for a proximity matrix within the 14 game genres. Among the categories, trivia and puzzle games were found to have nearest proximity, which means that the dispersion of frequencies among the nine keywords controlling game addictiveness have large 


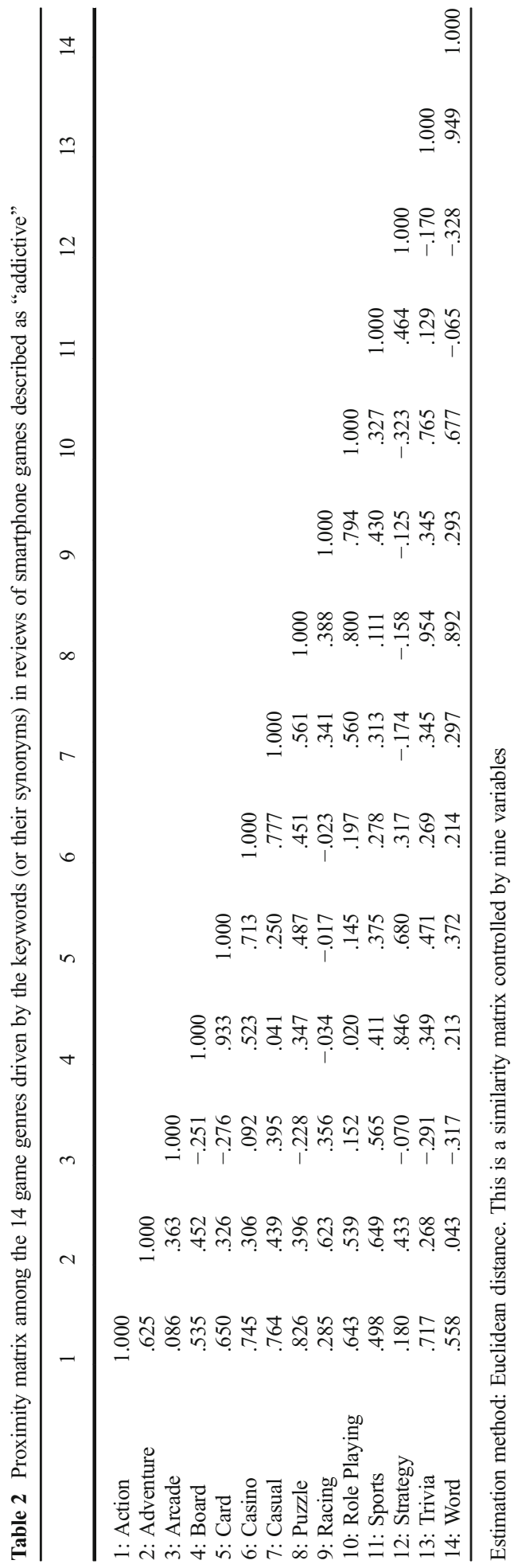




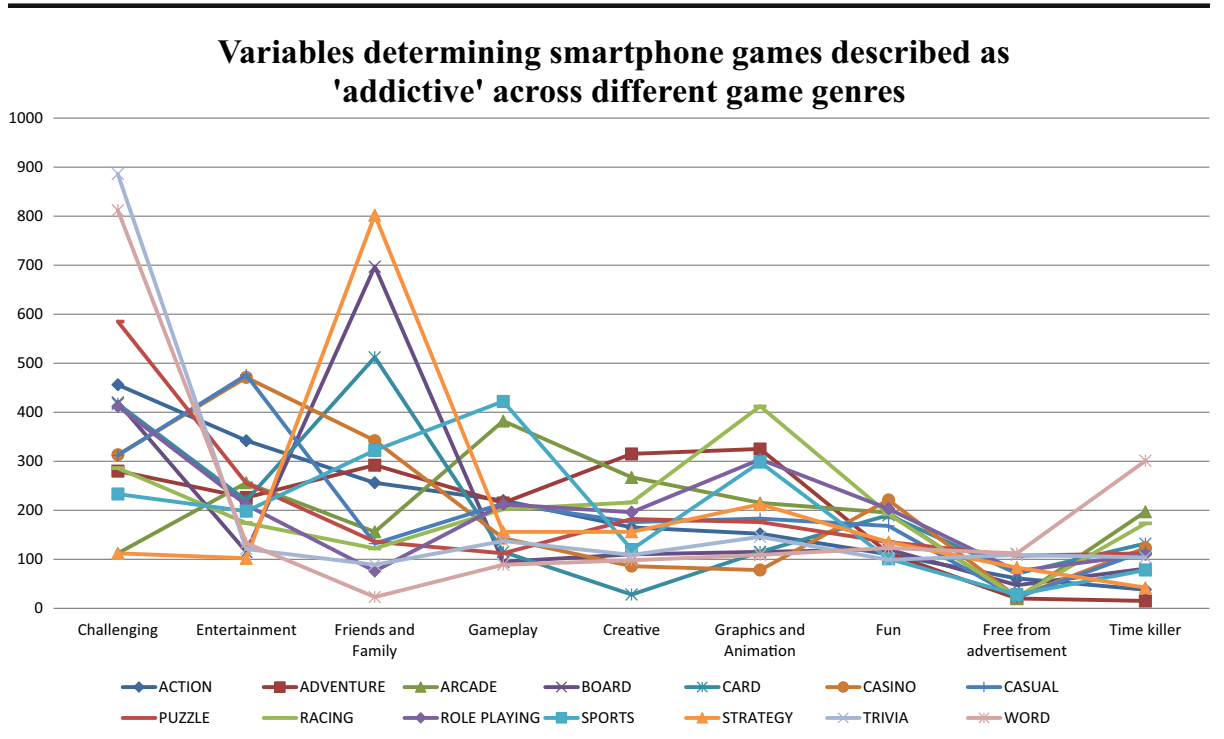

Fig. 1 Variables determining smartphone games described as "addictive" across different game genres

similarity. This clustering technique produced five separate game genre clusters. Table 3 provides the detailed cluster classification along with an explanation concerning each cluster.

\section{Discussion}

The present study carried out a content analysis of smartphone game reviews to analyze which variables are most commonly associated with "addictive" games by the players of these games. The findings demonstrated that the most common keyword (or its synonym) associated to addictive smartphone games was "challenging." Just over one-fifth of the 25,200 reviews $(22.37 \%)$ describing a smartphone game as "addictive" described the game as "challenging." Previous scholars have argued that "challenging" videogames have the capacity to be addictive (e.g., Liu 2011) but that related to games on other platforms rather than via smartphones. Compared to videogames of the 1990s, newer games appear to have higher levels of interactivity with peers, and are arguably more challenging. Many players strive for social affiliation and respect among their peers, guilds, and clans via their participation in challenging quests and gaining high scores in the games played. Many new games - including smartphone games - are stimulating a passion for challenge. Challenging games in and of themselves is not a concern as very few players become addicted to such games. However, if gamers themselves identify challenging games as being addictive, then at the very least, players should be educated about such games being a risk factor. Back in the 1990s, Griffiths and Hunt (1998) reported that only $10 \%$ of their respondents played video games because they were challenging (with $48 \%$ playing videogames primarily for fun). In the present study, the number of game reviews that used the keyword of "fun" was 2014 (7.99\%) compared to the keyword of "challenging" which was found in 5636 reviews (22.37\%). Although this is not comparing "like-with-like" (because the data are methodologically different and asking about motivations for playing videogames is different from the reasons as to why 
games are viewed as addictive by players), the data are suggestive that challenging games are increasingly preferred by players.

The study findings also support previous studies showing that videogames can be a social activity (e.g., Cole and Griffiths 2007; Griffiths et al. 2003; Yee 2006) by identifying "friends and family" as being associated with what makes a smartphone game addictive. The big difference here is that the game reviews suggest that the sociable element of playing with others may be one of the components associated with an "addictive" game. However, some research has indicated that social connections and relationships with others in the game can play an important role in the development of online game addictions (Kim et al. 2008; Hsu et al. 2009). Although it is a cliché, the ubiquity of the internet has made the world a global village. Friends and family can start new clans and play and interact as a group, work together strategically, build virtual relationships within the game, and attain social recognition from others. All of these things can be highly rewarding to players, and for a small minority, these constant rewards (i.e., reinforcements) may be addictive. In short, it is not hard to see why players think "friends and family" is an important factor in the potential addictiveness of a game.

Another key finding was that "graphics and animation" were also perceived by smartphone gamers as an important constituent of game addictiveness. Contemporary videogames can now gain captive attention via the use of motion capture, realistic animation graphics, augmented reality, and other visual innovations (Orosz et al. 2017). Graphical features are also heavily associated with good "gameplay" (King et al. 2010), another keyword that was associated with addictive smartphone games in the present study. In the taxonomy of structural characteristics of videogames developed by King et al. (2010), they identified graphics and presentation as key characteristics underlying motivation to play videogames. Graphics and sound are known to enhance gameplay experience (Salen and Zimmerman 2004) and can affect videogame player's cognitive actions (Griffiths and Nuyens 2017). Visual and perceptual innovation in the design of videogames will continue to improve via such mediums as virtual reality (VR) (Griffiths 2017). However, this is more likely to occur within massively multiplayer games rather than smartphone games (although smartphones themselves are increasingly being used as VR devices in themselves).

Research dating back to the 1990s has demonstrated that game genre has a contributory role in a videogame's addictiveness potential (Griffiths 1993; Griffiths and Hunt 1998). More recent studies have also shown that motivations and problematic gaming can differ between game types and genres (e.g., Ghuman and Griffiths 2012; Grüsser et al. 2007; Floros and Siomos 2012; Lee et al. 2007). The present study goes one stage further by clustering game categories based on players' self-perceived parameters associated with "addictive" games. Using Euclidean distance mapping, (a) Cluster 1 comprised action, adventure, sports, and arcade games, (b) Cluster 2 comprised board, card, and strategy games, (c) Cluster 3 comprised casino and casual games, (d) Cluster 4 comprised puzzle, trivia, and word games, and (e) Cluster 5 comprised racing and role-playing games (see Table 3). The clusters are segmented based on the keywords identified as components of an "addictive" game by players' smartphone game reviews. Future research should attempt to confirm or disconfirm the clusters identified here by both replication and use of different methodologies. It is recommended that future studies should also investigate game addiction respective to their game genre categories across different playing platforms (i.e., PCs, tablets, smartphones, etc.). 


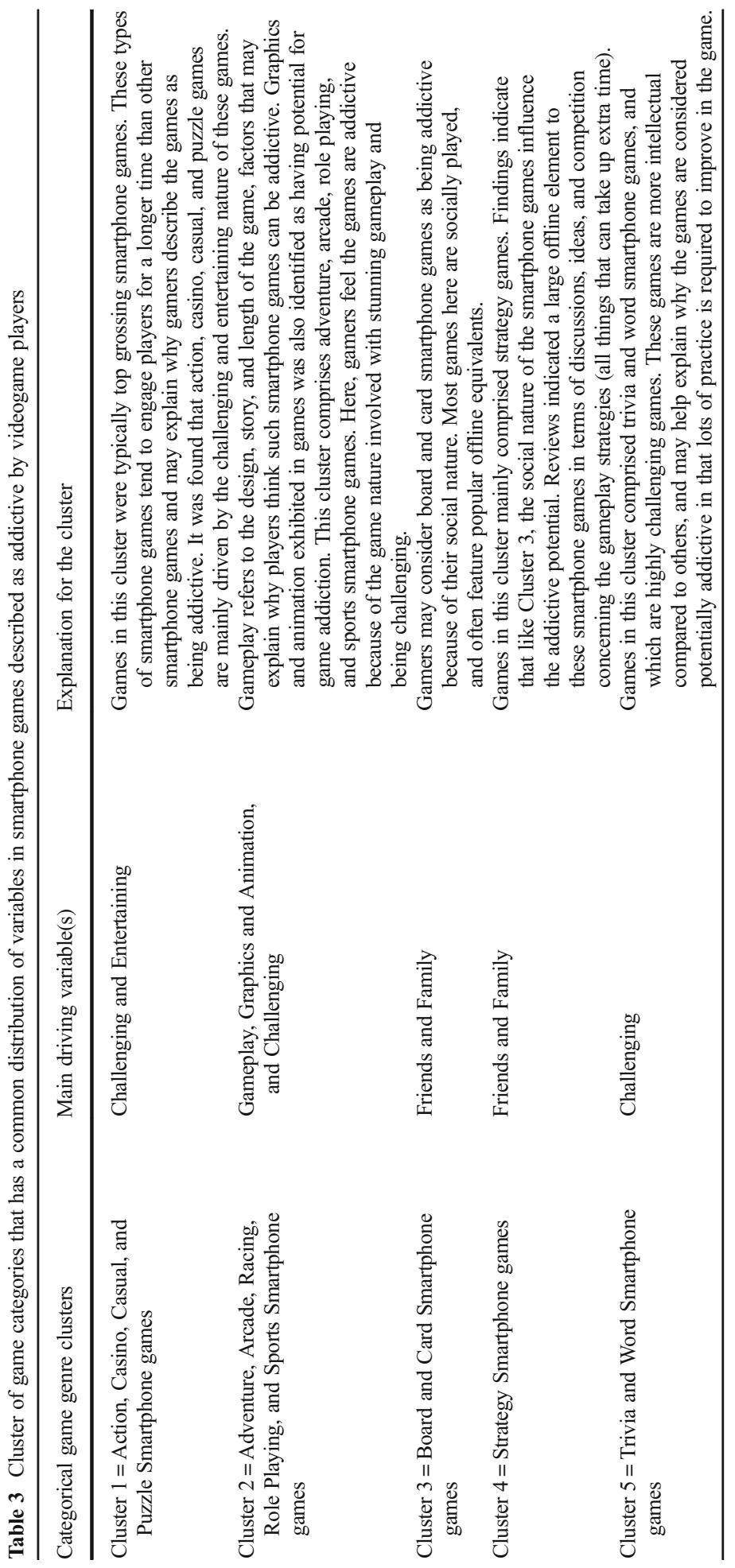


The study is not without its limitations. The present study relied on exploratory content analysis using simple frequency analysis and a proximity matrix technique. However, the use of such a simple design still provided valuable insights from a large sample of first-person game reviews $(n=25,200)$. The research team was unable to identify anything about the gamers who wrote the reviews (e.g., age, gender, and country of residence), but the research team believes that few reviews were written by more than one person and that, therefore, the sample size of gamers was large in comparison to most previously published studies. The lack of information about the gamers' profiles is a major limitation of the present paper. The data were purely qualitative in nature, but because of the large number of data points, they were converted into a numerical form. Despite the large dataset, one of the major limitations is that although all the game reviews were under the heading of "addictive," the gamers are likely to have used the words "addictive" and "addiction" in a different way and/or meaning than by the research team or those who work in the gaming addiction field. However, previous research has used similar types of data from online forums to examine players' perception of gaming addiction and reported that many players provided perceptive and articulate accounts of gaming addiction (e.g., Chappell et al. 2006; Griffiths et al. 2003). Future research can be carried out on the nine identified variables (i.e., the keywords), and further hypothetical models can be tested.

The findings in the present paper are of benefit to scholars, practitioners, and videogame developers. The main findings demonstrate that there are specific game characteristics that players perceive to be associated with "addictive" smartphone games (the most important of which appear to be that the games must be challenging, entertaining, and played with others) although other characteristics might be important depending upon game genre (such as having good graphics and state-of-the-art animation to enhance realism). The fact that different characteristics are seen as more associated with "addiction" depending upon game genre is an important consideration for any researchers examining the contribution made by structural characteristics in underpinning gaming addiction. It may also be the case that the importance of such structural characteristics will be different in different platforms (e.g., smartphone vs. PC) and this should also be a focus of future research. It may also be the case that gaming on casual games via one particular medium (e.g., via smartphone) might be less problematic than gaming on online multiplayer games (e.g., via PCs) as one recent study appeared to find (i.e., Lopez-Fernandez et al. 2018). At present, there is still little in the way of an established literature on smartphone gaming, therefore, the present paper is of existential value to this nascent field.

\section{Compliance with Ethical Standards}

Conflict of Interest The authors declare that they have no conflict of interests.

Ethical Approval All procedures performed in this study involving human participants were in accordance with the ethical standards of University's Research Ethics Board and with the 1975 Helsinki Declaration.

Informed Consent Not applicable. 


\section{Appendix 1}

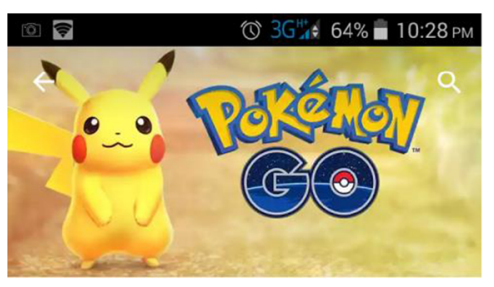

Pokémon GO

Niantic, Inc. * $3+81 \mathrm{MB}$

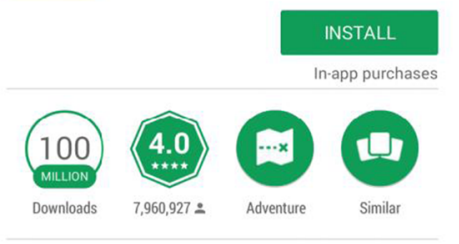

Step outside and catch Pokémon in the real world! Collect \& battle with others.

READ MORE
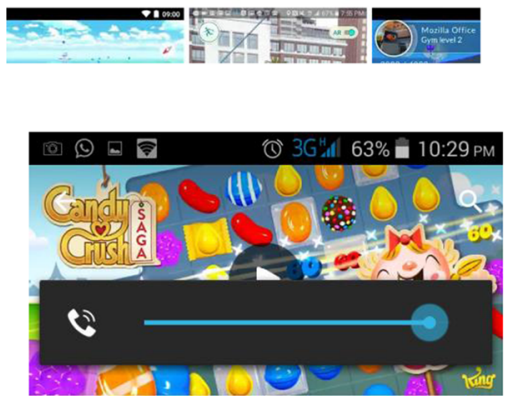

Candy Crush Saga

King *

$3^{+} \cdot 66 \mathrm{MB}$

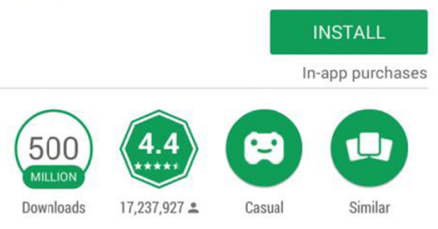

The sweetest game around!

READ MORE

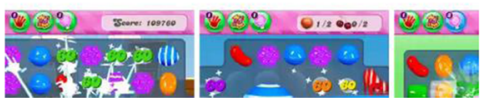

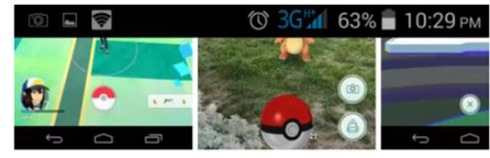

\section{$4 . \bigcup_{\substack{t, 1 \star \star \star * \\ 7,960,927}}$}

FEATURE RATINGS

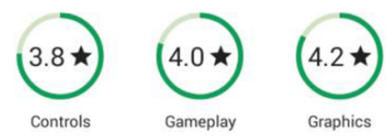

REVIEW HIGHLIGHTS

addictive

in 20,477 reviews

"This is an extremely addictive and popular game from a popular brand. There will be bugs..."

login problem in 5,766 reviews

"Over 2 weeks its showing authentication problem . Fix this issue as soon as possible..."

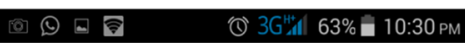

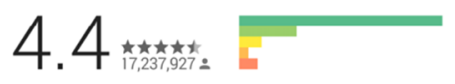

FEATURE RATINGS

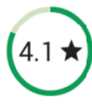

Controls

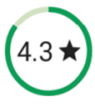

Gameplay

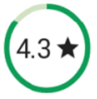

Graphics
REVIEW HIGHLIGHTS

addictive

in 182,349 reviews

"I really like this game. It's addicting. I do have a problem with the Daily Wheel though..."

challenging

in 27,388 reviews

"Be warned, you will become extremely addicted to this game! Its really fun $n$ challenging!..."

great time passer in 8,360 reviews "...Its a great way to pass time and feeling like you're giving your brain a nice exercise!" 


\section{Appendix 2}

\begin{tabular}{|c|c|c|c|}
\hline Action games & Adventure games & Arcade games & Board games \\
\hline Temple Run 2 & Pokemon Go & Subway Surfers & Ludo King \\
\hline Modern Combat 5 & Cycle Adventure & Temple Run & Carrom $3 D$ \\
\hline Shoot Hunter & Motu Patlu Game & Subway Runner & Ludo Neo Classic \\
\hline Doodle Army 2 & Criminal Case & Fruit Ninja & Chess Free \\
\hline Sniper Fury & Bounce Classic & Super: Jabber & Chess Online \\
\hline Shadow Fight 2 & Jungle Adventures 2 & Angry Birds & Chess prince \\
\hline Sniper $3 D$ & Subway Nano & Lep's World 2 & Real Carom: Multiplayer \\
\hline Endless Run Magic Stone & Pocket Army & Tom \& Jerry & Ludo $3 D$ \\
\hline Survival: Prison Escape & Hidden City: Mystery & Final Run & Real Chess \\
\hline Ninja Kung Fu Fighting & Swordigo & Apple shooter & Snakes and Ladders \\
\hline Card games & Casino games & Casual games & Puzzle games \\
\hline Callbreak Multiplayer & Teen Patti-Poker & My Talking Hank & Bubble Witch 3 \\
\hline Solitaire & Teen Patti-Gold & Candy Crush Saga & AB Blast \\
\hline Rummy Cards & Ultimate Teen Patti & My Talking Tom & Two Dots \\
\hline Yu-Gi-Oh! Duel Links & Teen Patti Live & My Talking Angels & Candy Blast Legend \\
\hline Ultimate Rummy Circle & Crazy Monkey Slot & Superstar Chef & Tic Tac Toe \\
\hline Callbreak-Ghochi & Teen Patti Royal & Cookie Crush & Flow Free \\
\hline Card Game 29 & Roulette Royal & Candy Crush Soda & Jigsaw Puzzle \\
\hline World Poker Series & $B I N G O$ & Bubble Shooter & Roll The Ball \\
\hline Call Break ++ & Zynga Poker & Chota Bheem & Cut The Rope \\
\hline Call Break Plus & Bingo Pop & Cooking In Kitchen & Escape The Prison \\
\hline Racing games & Role-playing games & Sports games & Strategy games \\
\hline Racing Time & Ben 10 Xenodrome & 8 Ball Pool & Clash of Clans \\
\hline Dr. Driving & Galaxy Legend & World Cricket & Invasion: Modern Empire \\
\hline Hill Climb Racing & Marvel Future Fight & Wrestling Revolution & Clash Royale \\
\hline Hill Climb Racing 2 & Star Wars: Galaxy & Big Bash 2016 & Star Wars: Force Arena \\
\hline Train Racing Games & Doraemon Repair & Real Cricket 16 & Spaceship Battles \\
\hline Asphalt 8: Airborne & DC Legends & Cricket Champion & Blaze of Battle \\
\hline Traffic Rider & My Teacher & Archery Master & Mobile Strike \\
\hline Moto Rider Go & City Crime Simulator & Score! Hero & Gungun Online \\
\hline City Racing $3 D$ & Lucid Sky & FIFA Mobile Soccer & Plants Vs. Zombies \\
\hline Moto Rider & School Of Dragons & ICC Pro Cricket & Lightning Rangers \\
\hline Trivia games & Word games & & \\
\hline Tricky Test 2 & Word Trek & & \\
\hline Tricky Test 3 & Word Search & & \\
\hline Quiz Up & Word Crush & & \\
\hline Quiz Logo Game & 4 Pics 1 Word & & \\
\hline Hex Stone & Spelling Master & & \\
\hline Think & English Guess & & \\
\hline Name The Pokemon & Word Brain & & \\
\hline Math All Levels & What Am I? & & \\
\hline Food Quiz & Heads Up & & \\
\hline GK Quiz 2016 & Psych! Outwit Friends & & \\
\hline
\end{tabular}

Open Access This article is distributed under the terms of the Creative Commons Attribution 4.0 International License (http://creativecommons.org/licenses/by/4.0/), which permits unrestricted use, distribution, and reproduction in any medium, provided you give appropriate credit to the original author(s) and the source, provide a link to the Creative Commons license, and indicate if changes were made. 


\section{References}

Billieux, J., Maurage, P., Lopez-Fernandez, O., Kuss, D. J., \& Griffiths, M. D. (2015). Can disordered mobile phone use be considered a behavioral addiction? An update on current evidence and a comprehensive model for future research. Current Addiction Reports, 2, 154-162.

Chappell, D., Eatough, V. E., Davies, M. N. O., \& Griffiths, M. D. (2006). EverQuest - It's just a computer game right? An interpretative phenomenological analysis of online gaming addiction. International Journal of Mental Health and Addiction, 4, 205-216.

Charlton, J. P., \& Danforth, I. D. (2007). Distinguishing addiction and high engagement in the context of online game playing. Computers in Human Behavior, 23(3), 1531-1548.

Charuvastra, A., Anderson, B. J., Friedmann, P. D., \& Stein, M. D. (2002). Perceived addiction treatment needs among alcohol using injection drug users. Journal of Addictive Diseases, 21(4), 93-107.

Cole, H., \& Griffiths, M. D. (2007). Social interactions in massively multiplayer online role-playing gamers. CyberPsychology \& Behavior, 10(4), 575-583.

Eiser, J. R., Van der Pligt, J., Raw, M., \& Sutton, S. R. (1985). Trying to stop smoking: Effects of perceived addiction, attributions for failure, and expectancy of success. Journal of Behavioral Medicine, 8(4), 321-341.

Fisher, S. (1994). Identifying video game addiction in children and adolescents. Addictive Behaviors, 19(5), 545553.

Gentile, D. A. (2009). Pathological video-game use among youth ages 8 to 18: A national study. Psychological Science, 20(5), 594-602.

Ghuman, D., \& Griffiths, M. D. (2012). A cross-genre study of online gaming: Player demographics, motivation for play, and social interactions among players. International Journal of Cyber Behavior, Psychology and Learning, 2(1), 13-29.

Griffiths, M. D. (1993). Are computer games bad for children? The Psychologist: Bulletin of the British Psychological Society, 6, 401-407.

Griffiths, M. (2000). Does internet and computer "addiction" exist? Some case study evidence. Cyberpsychology and Behavior, 3(2), 211-218.

Griffiths, M. D. (2010). The role of context in online gaming excess and addiction: Some case study evidence. International Journal of Mental Health and Addiction, 8(1), 119-125.

Griffiths, M. D. (2013). Adolescent mobile phone addiction: A cause for concern? Education and Health, 31, 7678.

Griffiths, M. D. (2017). The psychosocial impact of gambling in virtual reality. Casino and Gaming International, 29, 51-54.

Griffiths, M. D., \& Hunt, N. (1998). Dependence on computer games by adolescents. Psychological Reports, $82(2), 475-480$.

Griffiths, M. D., \& Nuyens, F. (2017). An overview of structural characteristics in problematic videogame playing. Current Addiction Reports, 4, 272-283.

Griffiths, M. D., Davies, M. N. O., \& Chappell, D. (2003). Breaking the stereotype: The case of online gaming. Cyberpsychology and Behavior, 6, 81-91.

Grubbs, J. B., Volk, F., Exline, J. J., \& Pargament, K. I. (2015). Internet pornography use: Perceived addiction, psychological distress, and the validation of a brief measure. Journal of Sex \& Marital Therapy, 41(1), 83106.

Grüsser, S. M., Thalemann, R., \& Griffiths, M. D. (2007). Excessive computer game playing: Evidence for addiction and aggression? CyberPsychology \& Behavior, 10(2), 290-292.

Hsu, S. H., Wen, M. H., \& Wu, M. C. (2009). Exploring user experiences as predictors of MMORPG addiction. Computers \& Education, 53(3), 990-999.

Kim, E. J., Namkoong, K., Ku, T., \& Kim, S. J. (2008). The relationship between online game addiction and aggression, self-control and narcissistic personality traits. European Psychiatry, 23(3), 212-218.

King, D., Delfabbro, P., \& Griffiths, M. (2010). Video game structural characteristics: A new psychological taxonomy. International Journal of Mental Health and Addiction, 8(1), 90-106.

Kuss, D. J., \& Griffiths, M. D. (2012). Internet gaming addiction: A systematic review of empirical research. International Journal of Mental Health and Addiction, 10(2), 278-296.

Lee, M. S., Ko, Y. H., Song, H. S., Kwon, K. H., Lee, H. S., Nam, M., \& Jung, I. K. (2007). Characteristics of internet use in relation to game genre in Korean adolescents. Cyberpsychology \& Behavior, 10(2), 278-285.

Lemmens, J. S., Valkenburg, P. M., \& Peter, J. (2011). Psychosocial causes and consequences of pathological gaming. Computers in Human Behavior, 27, 144-152.

Lim, S., \& Lee, J. E. R. (2009). When playing together feels different: Effects of task types and social contexts on physiological arousal in multiplayer online gaming contexts. CyberPsychology \& Behavior, 12(1), 59-61.

Liu, E. Z. F. (2011). Avoiding internet addiction when integrating digital games into teaching. Social Behavior and Personality, 39(10), 1325-1335. 
Longman, H., O’Connor, E., \& Obst, P. (2009). The effect of social support derived from world of Warcraft on negative psychological symptoms. CyberPsychology \& Behavior, 12(5), 563-566.

Lopez-Fernandez, O., Männikkö, N., Kääriäinen, M., Griffiths, M. D., \& Kuss, D. J. (2018). Mobile gaming does not predict smartphone dependence: a cross-cultural study between Belgium and Finland. Journal of Behavioral Addictions, 1-12. https://doi.org/10.1556/2006.6.2017.080.

Mehroof, M., \& Griffiths, M. D. (2010). Online gaming addiction: The role of sensation seeking, self-control, neuroticism, aggression, state anxiety, and trait anxiety. Cyberpsychology, Behavior, and Social Networking, 13(3), 313-316.

Orosz, G., Zsila, A., Bőthe, B., Tóth-Király, I., Király, O., Griffiths, M. D., \& Demetrovics, Z. (2017). An empirical study on the motivations underlying augmented reality games: The case of Pokémon go. Personality and Individual Differences. https://doi.org/10.1016/j.paid.2017.06.024.

Peters, C. S., \& Malesky, L. A. (2008). Problematic usage among highly-engaged players of massively multiplayer online role playing games. CyberPsychology \& Behavior, 11, 480-483.

Pontes, H., Stavropoulos, V., \& Griffiths, M. D. (2017). Measurement invariance of the internet gaming disorder scale-short-form (IGDS9-SF) between the United States of America, India and the United Kingdom. Psychiatry Research, 257, 472-478.

Rehbein, F., Kleimann, M., \& Mossle, T. (2010). Prevalence and risk factors of video game dependency in adolescence: Results of a German nationwide survey. Cyberpsychology, Behavior and Social Networking, 13, 269-277.

Salen, K., \& Zimmerman, E. (2004). Rules of play: Game design fundamentals. Cambridge, MA: MIT Press.

van Rooij, A. J., Schoenmakers, T. M., van de Eijnden, R., \& van de Mheen, D. (2010). Compulsive internet use: the role of online gaming and other internet applications. Journal of Adolescent Health, 47, 51-57.

Wang, C. C., \& Wang, C. H. (2008). Helping others in online games: Prosocial behavior in cyberspace. CyberPsychology \& Behavior, 11(3), 344-346.

Yee, N. (2006). Motivations for play in online games. CyberPsychology \& Behavior, 9(6), 772-775. 